\title{
Differential acclimation capacity to frost in sugarcane varieties grown under field conditions
}

\author{
Philippus D.R. van Heerden ${ }^{1,2}$ \\ ${ }^{1}$ South African Sugarcane Research Institute, Mount Edgecombe, 4300, South Africa. \\ ${ }^{2}$ Department of Plant Production and Soil Science, University of Pretoria, Pretoria, 0028, South Africa \\ Corresponding Author; Philippus D.R. van Heerden, Fax 002731 5087597, e-mail \\ riekert.vanheerden@sugar.org.za
}

\begin{abstract}
In certain sugarcane (Saccharum spp. hybrids) production regions of the world, including South Africa, frost frequently occurs. Great demand exists for frost tolerant sugarcane varieties as production in these areas could become more profitable. Two Louisiana (USA) varieties, known to yield high sugar even when immature (LCP 85-384 and HOCP 96-540), and two South African varieties (N21 and N36) were evaluated in a field trial for frost tolerance. O-J-I-P chlorophyll a fluorescence transients were recorded in youngest fully-expanded leaves of these varieties on several occasions before and following exposure to frost. Analysis of these transients revealed that varieties N36 and LCP 85-384 were capable of cold acclimation following the first frost, while N21 and HOCP 96-540 lacked similar capability. Exposure to further frosts altered the fluorescence transients in a variety-specific fashion, with recovery in N36 and LCP 85384 towards baseline kinetics, but with further deterioration in N21 and HOCP 96-540. Between the first frost and harvest, estimated recoverable crystal (ERC) content values in cane stalks of N36 and LCP $85-384$ increased by 26\% and 20\% respectively, while in N21 and HOCP 96-540 ERC content values only increased by $8 \%$ and $11 \%$ respectively. Consequently, N36 and LCP 85-384 ultimately achieved the highest ERC yields (tons/hectare). The ability to maintain high ERC accumulation capacity for longer following frost could be an important factor determining sugarcane yield performance in
\end{abstract}


frost-prone areas. In addition, O-J-I-P fluorescence rise kinetics show promise as a rapid screening tool for assessment of cold acclimation potential in sugarcane.

\title{
Key words
}

Chlorophyll a fluorescence; Cold acclimation; Frost tolerance; Sucrose accumulation; Sugarcane

\begin{abstract}
Abbreviations
ERC - Estimated recoverable crystal; NADP-MDH - NAPD-malate dehydrogenase; $\mathrm{PI}_{\mathrm{ABS}}$ - Performance index.
\end{abstract}

\section{Introduction}

Due to their mostly tropical and sub-tropical distribution, $\mathrm{C}_{4}$ plants generally are more cold-sensitive than $C_{3}$ plants (Berry and Björkman 1980). Cold tolerance also differs between the three $\mathrm{C}_{4}$ subtypes, with those species belonging to the NADP-malic enzyme (NADP-ME) subtype generally being the most cold-sensitive (Edwards et al. 1985). In a recent study the effects of low temperatures on $\mathrm{C}_{4}$ and $\mathrm{C}_{3}$ sub-tropical grasses were compared in Alloteropsis semialata, a unique species with both $\mathrm{C}_{4}$ and $\mathrm{C}_{3}$ subspecies cooccurring in sub-tropical parts of South Africa (Osborne et al. 2008). These authors found high levels of freezing stress injury in leaves of both sub-species in the unhardened state. However, a prolonged chilling treatment introduced as a hardening treatment before the freezing stress, reduced injury in the $\mathrm{C}_{3}$ subspecies by $50 \%$, but not in the $\mathrm{C}_{4}$ subspecies. It was concluded that the $\mathrm{C}_{4}$ subtype lacked the ability for cold acclimation (Osborne et al. 2008). However, leaves of some $\mathrm{C}_{4}$ grass species can resist freezing injury at temperatures of less than $-10^{\circ} \mathrm{C}$ (Sage and Kubien 2007). Therefore, although tolerance to freezing is not completely absent, most $\mathrm{C}_{4}$ grasses do not demonstrate significant cold acclimation capability, and are regarded as sensitive to freezing stress (Rowley et al. 1975; Rowley 1976).

As a consequence of its recognised sensitivity to low temperature, cultivation of sugarcane in frost-prone areas across the world often necessitates shorter growing cycles 
in order to escape the detrimental after-effects of frost damage such as leaf and apical meristem mortality, profuse side-shooting and cane deterioration (Eggleston et al. 2004). Frost is very common in the Midlands region of Kwazulu-Natal (South Africa), especially in valley bottoms. Harvesting sugarcane annually in the Midlands region is less profitable because the full yield potential of the crop, which is usually attained after 18-24 months, is not yet realised after only twelve months of growth. Hence, there is urgent need for identifying frost tolerant varieties, or varieties yielding high sugar even when harvested young, to increase profitability in frost affected areas.

Low temperatures have been shown to negatively affect photosynthesis in sugarcane, in particular in the form of less efficient energy transfer to reaction centres and slower reduction of the primary electron acceptors of photosystem II (PSII) (Ebrahim et al. 1998). In addition, marked reduction in the activities of NADP-malate dehydrogenase (NADP-MDH) and pyruvate, orthophosphate dikinase (PPDK) have also been reported in sugarcane exposed to low temperature ( $\mathrm{Du}$ et al. 1999). These authors proposed that the inhibition of NADP-MDH and PPDK activity limited $\mathrm{CO}_{2}$ assimilation capacity with subsequent photoinhibition and upstream damage to the electron transport systems. These results suggest that electron transport capacity is a main target during low temperature stress and that chlorophyll a fluorescence might be a sensitive tool for probing the degree of damage and acclimation responses in sugarcane. Although we are not aware of any studies in sugarcane, chlorophyll a fluorescence has been used successfully in the past to assess the effects of freezing stress and subsequent recovery in winter wheat cultivars (Rapacz 2007; Rapacz et al. 2011). However, a limitation of these, and numerous other studies using chlorophyll a fluorescence to probe stress effects in crop plants, is that the observed effects is very seldom related to actual impact on yield. Many of these studies are typically also conducted under controlled growth conditions in potted plants, where it is extremely difficult to realistically mimic impacts of stress factors on yield. Moreover, it has also been suggested that controlled growth environments might often introduce artefacts, which then produces an unrealistic picture of cold acclimation processes (Trischuk et al. 2006).

The research reported in this paper addressed these limitations and lack of current understanding by performing field evaluation of the response of different sugarcane 
varieties to frost. A further novel aspect of the work was the subsequent relating of these responses to sugar accumulation and yield. This study was premised on the hypothesis that varying degrees of cold acclimation capacity exists in sugarcane and that field evaluation involving chlorophyll a fluorescence measurements would be a suitable approach to investigate these responses and subsequent impacts on yield.

\section{Materials and methods}

Variety selection

Two quick-maturing imported sugarcane varieties (LCP 85-384 and HOCP 96-540) from Louisiana (USA), known to yield high sugar even at a relatively young age of only $8-9$ months (Dufrene and Tew 2004; Eggleston et al. 2004), and two well-known South African varieties (N21 and N36) were included in this study. All varieties were propagated using the NovaCane ${ }^{\circledR}$ tissue culture protocol (Snyman et al. 2008) to ensure disease-free material for field planting.

\section{Field trial details}

A field trial was established in a frost-prone valley-bottom on a commercial farm near the town of New Hanover in the Midlands-North region of Kwazulu-Natal, South Africa. Trial plots of sufficient area to accommodate five sugarcane rows $10 \mathrm{~m}$ long spaced $1 \mathrm{~m}$ apart were marked out. Soil samples from $0-20 \mathrm{~cm}$ depth were collected from each of the plots and subjected to chemical and soil texture analyses. The soil characteristics of each plot were then used with Principal Component Analysis (ADE-4 software) to map the variability across the trial area. Relationships between plots were examined with cluster analysis and individual plots assigned to five replicates per variety in a way that would minimise potential effects of soil variability. The trial was planted on 18 October 2007. Trial management by the farmer was done as per usual commercial practice. The first light frost occurred during mid-June 2008 and was followed by a series of heavier frosts between 26 June and 3 July 2008. The heaviest frost occurred on 11 July 2008. The trial was harvested on 23 July 2008. 
Chlorophyll a fluorescence measurements

For a physiological assessment of frost effects on the varieties O-J-I-P chlorophyll a fluorescence transients (Strasser and Govindjee 1992) were recorded in dark adapted youngest fully-expanded leaves. These measurements were started on 25 April 2008, approximately six weeks before the first frost and were continued until shortly before harvest. Measurements were repeated approximately every two weeks, which included a measurement a few days before the first frost, a few days after the first frost and also after several additional frosts. On each occasion measurements were done on the broadest midsection of the youngest fully expanded leaves of four randomly-selected plants per replicate plot. In total 20 plants per variety were measured on each occasion. Measurements were conducted with a PEA fluorescence meter (Hansatech Instruments Ltd., King's Lynn, Norfolk, PE 30 4NE, UK). The transients were induced by a red light (peak at $650 \mathrm{~nm}$ ) of $3200 \mu \mathrm{mol} \mathrm{m}{ }^{-2} \mathrm{~s}^{-1}$ provided by the PEA instrument through an array of six light-emitting diodes.

The JIP-test (Strasser and Strasser 1995) was subsequently employed to analyse each recorded transient. The following data from the original measurements were used: maximal fluorescence intensity $\left(\mathrm{F}_{\mathrm{M}}\right)$; fluorescence intensity at $50 \mu$ s (considered as $\mathrm{F}_{0}$ ); fluorescence intensity at $300 \mu \mathrm{s}\left(\mathrm{F}_{300 \mu \mathrm{s}}\right)$ required for calculation of the initial slope $\left(\mathrm{M}_{0}\right)$ of the relative variable fluorescence $(\mathrm{V})$ kinetics; the fluorescence intensity at $2 \mathrm{~ms}$ (the $\mathrm{J}$ step) denoted as $F_{J}$. $V_{J}$ was calculated as $\left(F_{J}-F_{0}\right) /\left(F_{M}-F_{0}\right)$. The data was used to calculate (equation 1) the Performance index $\left(\mathrm{PI}_{\mathrm{ABS}}\right)$, which is a sensitive indicator of electron transport efficiency (Krüger et al. 1997; Strasser et al. 2000; Force et al. 2003; Strauss et al. 2007).

$$
\mathrm{PI}_{\mathrm{ABS}}=\frac{1-\left(\mathrm{F}_{0} / \mathrm{F}_{\mathrm{M}}\right)}{\mathrm{M}_{0} / \mathrm{V}_{\mathrm{J}}} \cdot \frac{\mathrm{F}_{\mathrm{M}}-\mathrm{F}_{0}}{\mathrm{~F}_{0}} \cdot \frac{1-\mathrm{V}_{\mathrm{J}}}{\mathrm{V}_{\mathrm{J}}}
$$

Yield parameters

A 12-stalk sample was taken from each plot just prior to the first frost to determine a range of milling quality characteristics, including estimated recoverable crystal (ERC) 
content, which is an estimate of the recoverable value of sugarcane delivered to the sugar mill. The ERC content (\%) was calculated per stalk fresh weight (FW) as (equation 2):

$$
\text { ERC content }(\%)=\mathrm{aS}-\mathrm{bN}-\mathrm{cF} \quad \text { (Eq. 2) }
$$

where $\mathrm{S}=$ sucrose content (\%) per stalk FW; $\mathrm{N}=$ non-sucrose content (\%) per stalk FW; $\mathrm{F}=$ fibre content per stalk FW and $\mathrm{a}, \mathrm{b}, \mathrm{c}$ are industry determined factors representing the loss of each component $(0.978,0.535$, and 0.018 respectively) during sucrose extraction at the mill. At harvest, the three centre cane rows in each plot were cut and bundled by hand and weighed using a hydraulic grab apparatus equipped with a load cell to determine cane yield (tons) per hectare (ha). Another 12-stalk sample was taken from each plot for calculation of ERC content at harvest (equation 2). The ERC yield (t/ha) per plot was subsequently estimated as (equation 3):

ERC yield $(\mathrm{t} / \mathrm{ha})=$ ERC content $\mathrm{x}$ Cane yield

(Eq. 3)

Statistical analysis

All the variables were analysed using one-way ANOVA. Each variable was first tested for normality and homogeneity using the Shapiro-Wilk and Bartlett tests respectively (Genstat v.14). The post hoc test used was the least significant difference (LSD) (5\%) test.

\section{Results}

Effects of frost on the performance index $\left(\mathrm{PI}_{\mathrm{ABS}}\right)$

In Fig. 1a and $\mathrm{b}$ the Performance index $\left(\mathrm{PI}_{\mathrm{ABS}}\right)$ values are shown for the four varieties recorded from 6 weeks before the first frost (first four data points including one marked with black arrow), five days after the first frost (data point marked with dark-grey arrow), after several subsequent frosts (data point marked with light-grey arrow) and until shortly before harvest. All varieties showed a decline in $\mathrm{PI}_{\mathrm{ABS}}$ values following the first light frost event (decline in $\mathrm{PI}_{\mathrm{ABS}}$ values from black to dark-grey arrow). This decline in $\mathrm{PI}_{\mathrm{ABS}}$ values (relative to pre-frost values marked by black arrows) were $20 \%, 30 \%, 14 \%$ and 


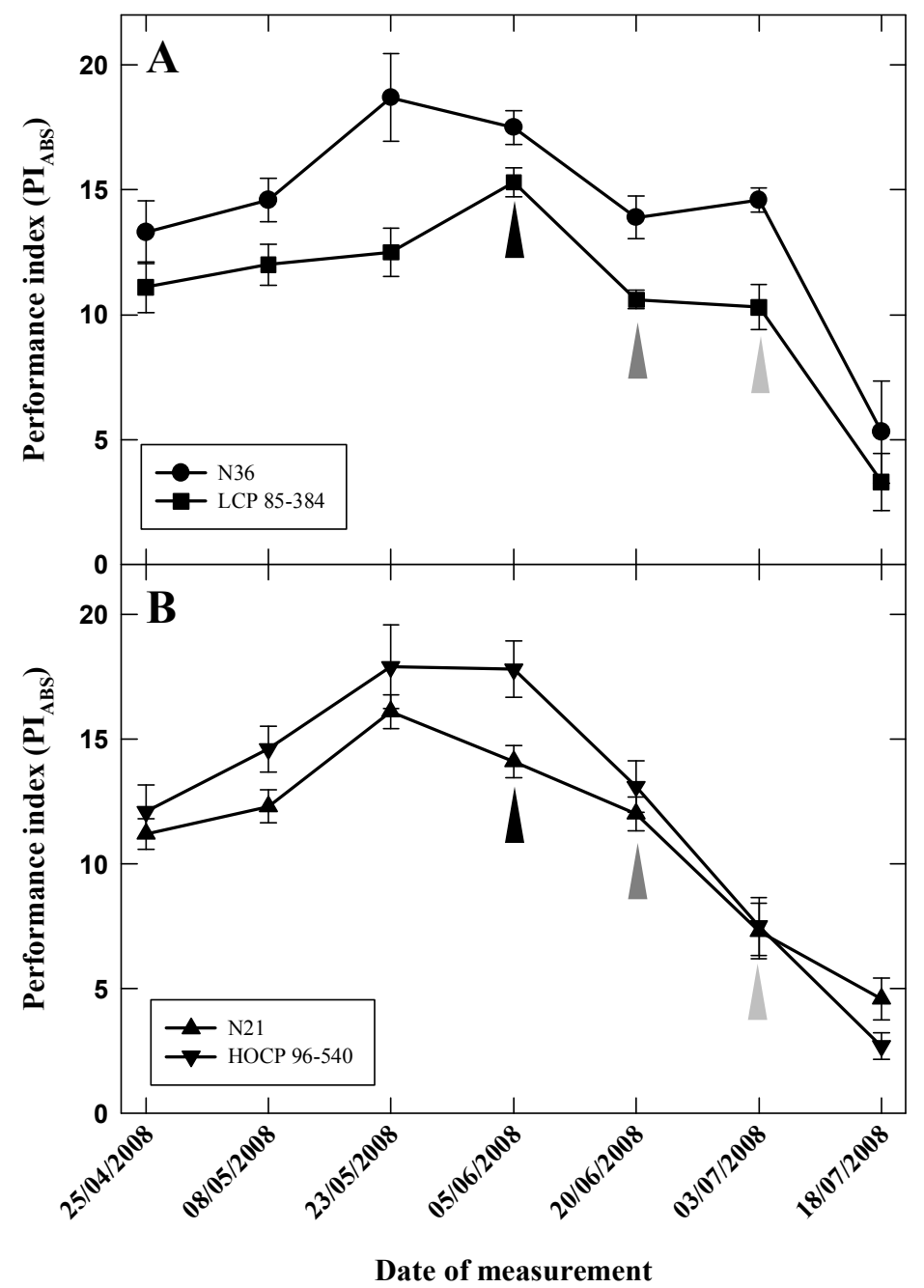

Fig 1.

The effect of frost on Performance Index $\left(\mathrm{PI}_{\mathrm{ABS}}\right)$ values in the sugarcane varieties N36, LCP 85-384 (a) and N21, HOCP 96540 (b). Measurements were taken from 6 weeks before the first frost (first four data points including one marked with black arrow), five days after the first frost (dark-grey arrow), after several subsequent frosts (light-grey arrow) and until shortly before harvest 
$26 \%$ in N36, LCP 85-384, N21 and HOCP 96-540 respectively. However, following additional frost events (time period indicated between dark-grey and light-grey arrows) N36 and LCP 85-384 maintained $\mathrm{PI}_{\mathrm{ABS}}$ values at similar levels for at least two weeks longer (Fig. 1a) than the other two varieties. In N21 and HOCP 96-540 these additional frosts led to a large decline in $\mathrm{PI}_{\mathrm{ABS}}$ values (Fig. 1b). At this point in time (marked by light-grey arrows) the decline in $\mathrm{PI}_{\mathrm{ABS}}$ values (relative to pre-frost values marked by black arrows) was $16 \%, 32 \%, 48 \%$ and $57 \%$ in N36, LCP 85-384, N21 and HOCP 96540 respectively clearly illustrating the additional decline that occurred in N21 and HOCP 96-540. Ultimately, the most severe frost event that occurred just prior to harvest led to severe damage in all varieties.

Effects of frost on O-J-I-P fluorescence rise kinetics

Illumination of the dark-adapted leaves induced characteristic changes in the intensity of chlorophyll a fluorescence, known as the Kautsky effect (Kautsky and Hirsch 1931). When the Kautsky transient is plotted on a logarithmic time scale the fluorescence rise kinetics are polyphasic, clearly exhibiting two intermediate steps known as $\mathrm{J}$ and I (Strasser and Govindjee 1992), hence the notation O-J-I-P for the fast rise of the fluorescence transient. In Fig. 2 O-J-I-P fluorescence transients recorded in fully expanded leaves of the four varieties a few days before the first frost (5 June 2008), a few days after the first frost (20 June 2008), and also after several additional frosts (3 July $2008)$ are shown. The transients were normalized at the $\mathrm{O}\left(\mathrm{F}_{0}\right)$ and $\mathrm{P}\left(\mathrm{F}_{\mathrm{M}}\right)$ steps in order to reveal changes in the shape of the transients between these two extremes more clearly. In all four varieties the frost-induced changes in the shape of these transients are clearly visible.

The variety-specific effects of frost on the O-J-I-P fluorescence rise kinetics were visualised by the construction of difference in variable fluorescence $(\Delta \mathrm{V})$ curves as detailed by Strauss et al. (2007). For the construction of $\Delta \mathrm{V}$ curves the normalised values (Fig. 2) derived from transients recorded after the first light frost (20 June 2008), and after several subsequent frosts (3 July 2008), were subtracted from the normalised values derived from transients recorded prior to the first frost (5 June 2008). The black lines in Fig. 3 represents the result (zero values) obtained after subtraction of the normalised 


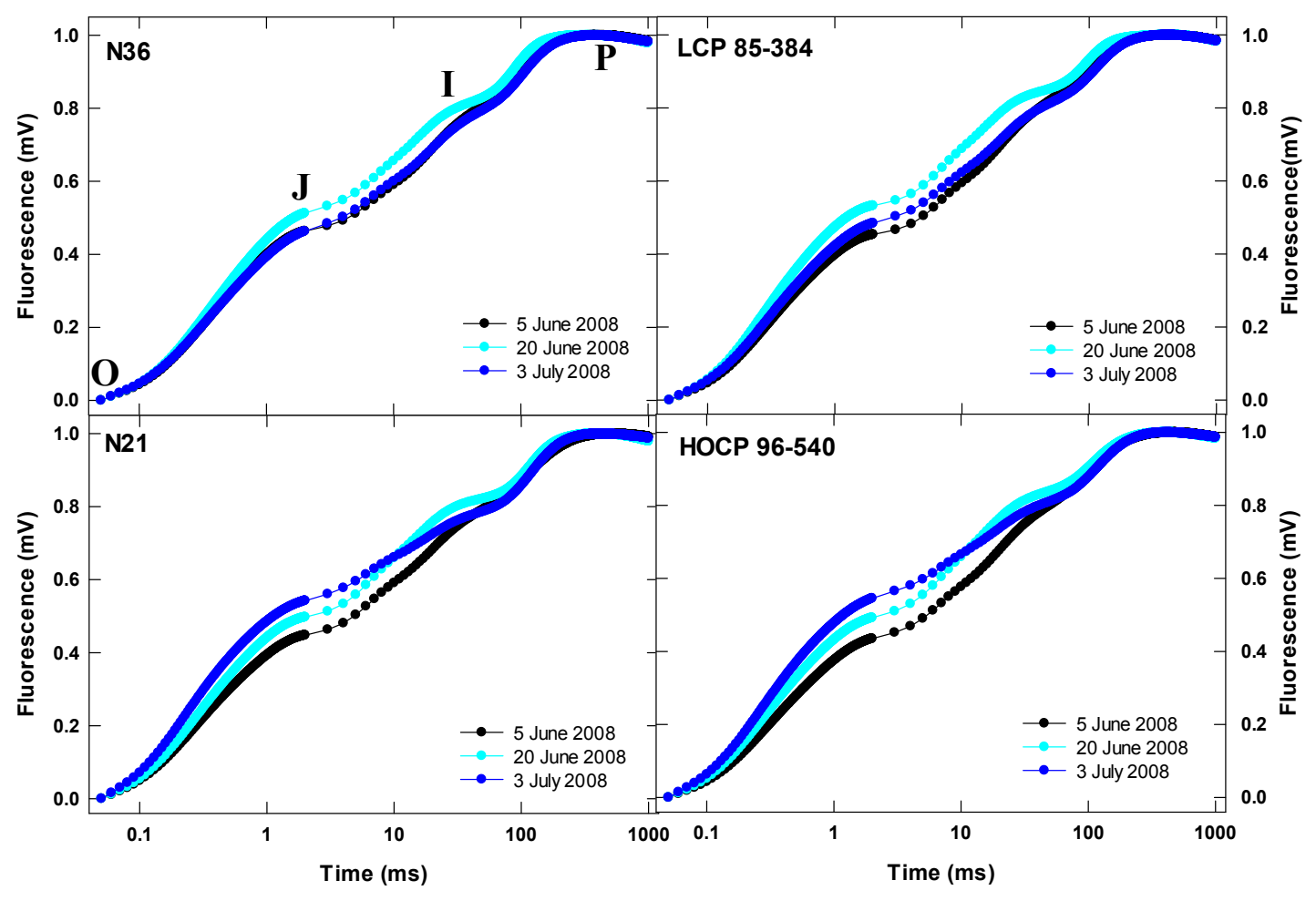

Fig 2.

Effects of dark chilling on O-J-I-P fluorescence transients (normalised between $\mathrm{O}$ and $\mathrm{P}$ ) recorded in fully expanded leaves of the four sugarcane varieties. Transients were recorded pre-frost ( 5 June, black curves), after the first frost (20 June, light-blue curves) and again after several additional mild frosts (3 July, dark-blue curves). The position of the main steps $(\mathrm{O}, \mathrm{J}$, I and P) is indicated in the top left-hand figure 
values derived from transients recorded prior to the first frost (5 June 2008) from itself in order to produce a zero baseline. Any deviation (from the black zero baseline) in $\Delta \mathrm{V}$ curves derived after the first light frost (light-blue curves), and after several subsequent frosts (dark-blue curves) thus illustrates the degree of alteration in O-J-I-P fluorescence rise kinetics induced by frost in the four varieties (Fig. 3).

Construction of these $\Delta \mathrm{V}$ curves, using the pre-frost O-J-I-P fluorescence rise kinetics (5 June 2008, black horizontal lines) for each variety as a baseline, revealed that the first frost (20 June 2008, light-blue curves) induced a perturbation in kinetics of very similar shape and magnitude in all four varieties (Fig. 3). However, after several subsequent frosts ( 3 July 2008, dark-blue curves) the kinetics were altered in a varietyspecific fashion, with clear recovery in N36 and LCP 85-384 towards baseline kinetics (downward pointing green arrows), but with further deterioration in N21 and HOCP 96540 (upward pointing green arrows), with the peaking of deviation located at $2 \mathrm{~ms}$ (Jstep). These changes in O-J-I-P fluorescence rise kinetics corresponded well with the changes in $\mathrm{PI}_{\mathrm{ABS}}$ values where all four varieties experienced a decline following the first light frost (Fig. 1, dark-grey arrows \& Fig. 3, light-blue curves) but where N36 and LCP 85-384 then stabilised $\mathrm{PI}_{\mathrm{ABS}}$ values at similar levels for at least two weeks longer while N21 and HOCP 96-540 experienced further declines (Fig. 1, light-grey arrows \& Fig. 3, dark-blue curves).

Effects of frost on yield parameters

Samples were taken from each treatment plot just prior to the first frost, and again at harvest, to determine the effect of frost on accumulation of estimated recoverable crystal (ERC) in the stalks of the four varieties. These results showed that N36 and LCP 85-384 increased ERC content (\%) by $26 \%$ and $20 \%$ between the pre-frost state and harvest, compared to N21 and HOCP 96-540, where the increases were only $8 \%$ and 11\% (Fig. 4). In the case of N36 and LCP 85-384 the increases in ERC content were statistically significant, while the much smaller increases in N21 and HOCP 96-540 were not.

Although N36 and N21 had similar cane yields at harvest (results not shown), N36 had 30\% higher ERC yields (t/ha) than N21 (Fig. 5). Likewise, the reported ERC yield 


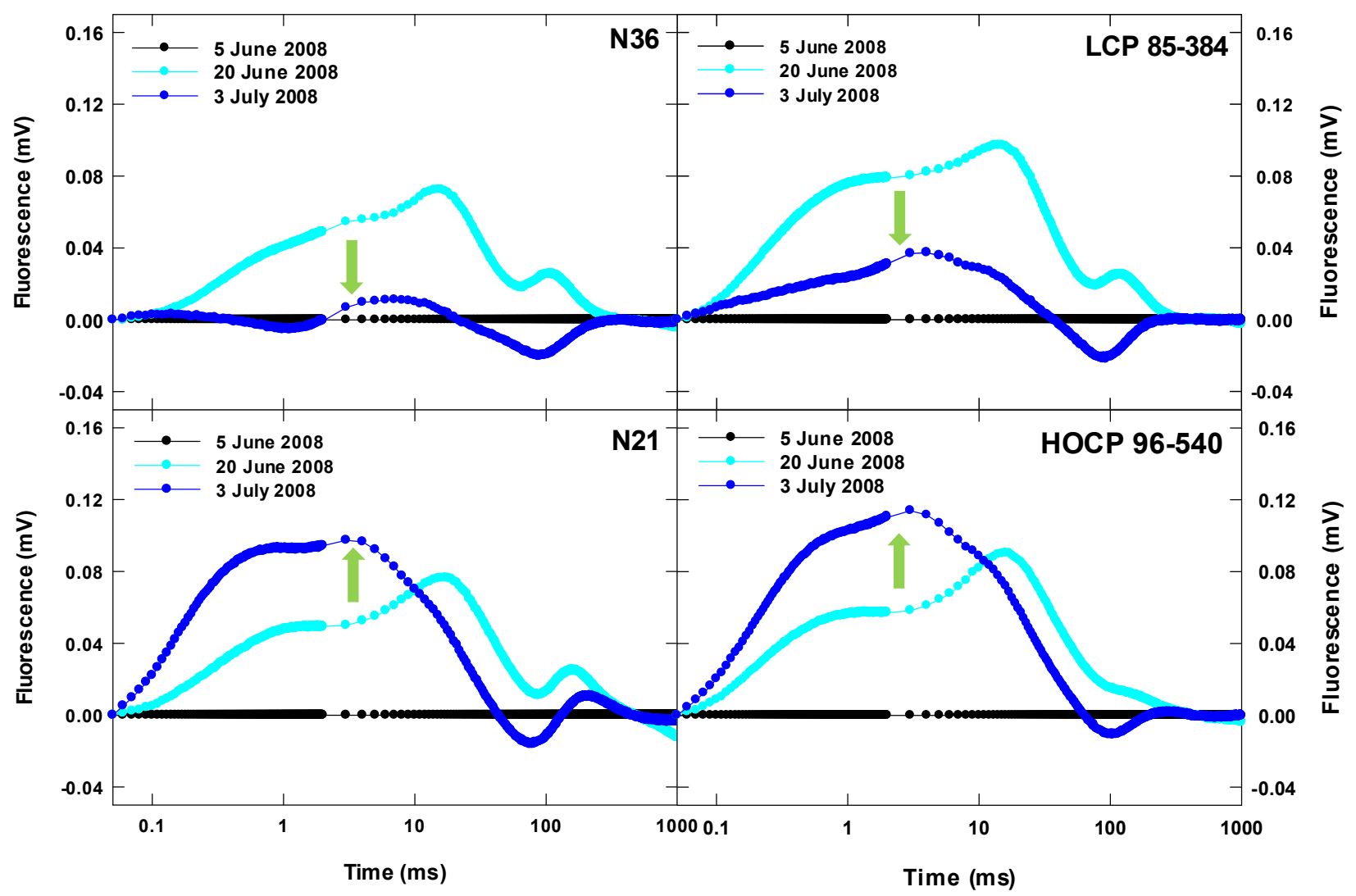

Fig 3.

Difference in variable fluorescence $(\Delta \mathrm{V})$ curves constructed by subtraction of normalised $(\mathrm{O}-\mathrm{P})$ fluorescence values recorded prefrost ( 5 June, black horizontal baseline) from those recorded after the first frost (20 June, light-blue curves) or after several additional mild frosts (3 July, dark-blue curves) 


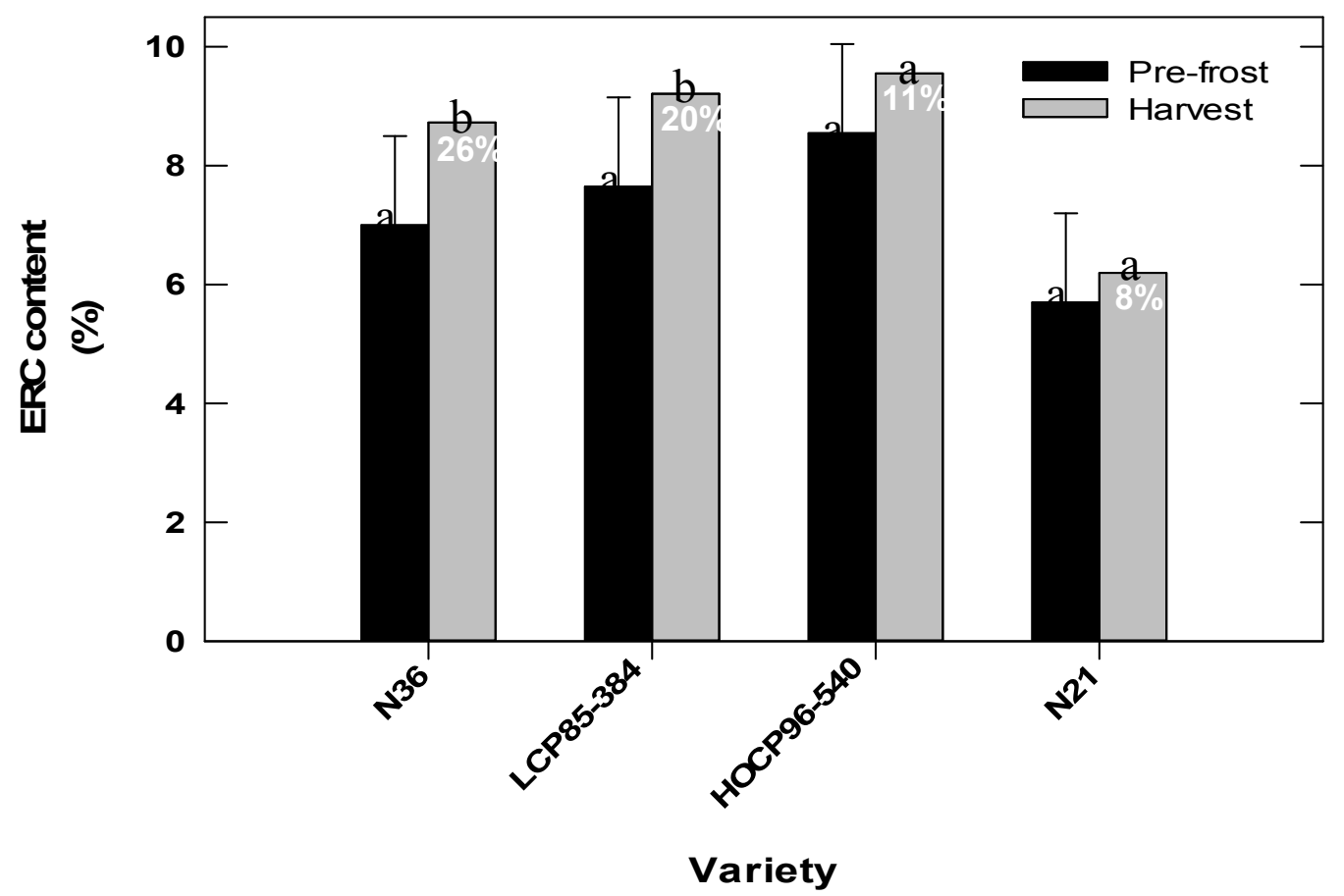

Fig 4.

Stalk ERC content (\%) in the four varieties pre-frost (black bars) and at harvest (grey bars). The \% values indicates how much higher the ERC content was at harvest, relative to the pre-frost state, and different lowercase letters indicate significant differences $(p<0.05)$ between the two sampling points for each variety. Error bars indicate least significant difference at $p<0.05\left(\operatorname{LSD}_{0.05}\right)$ 


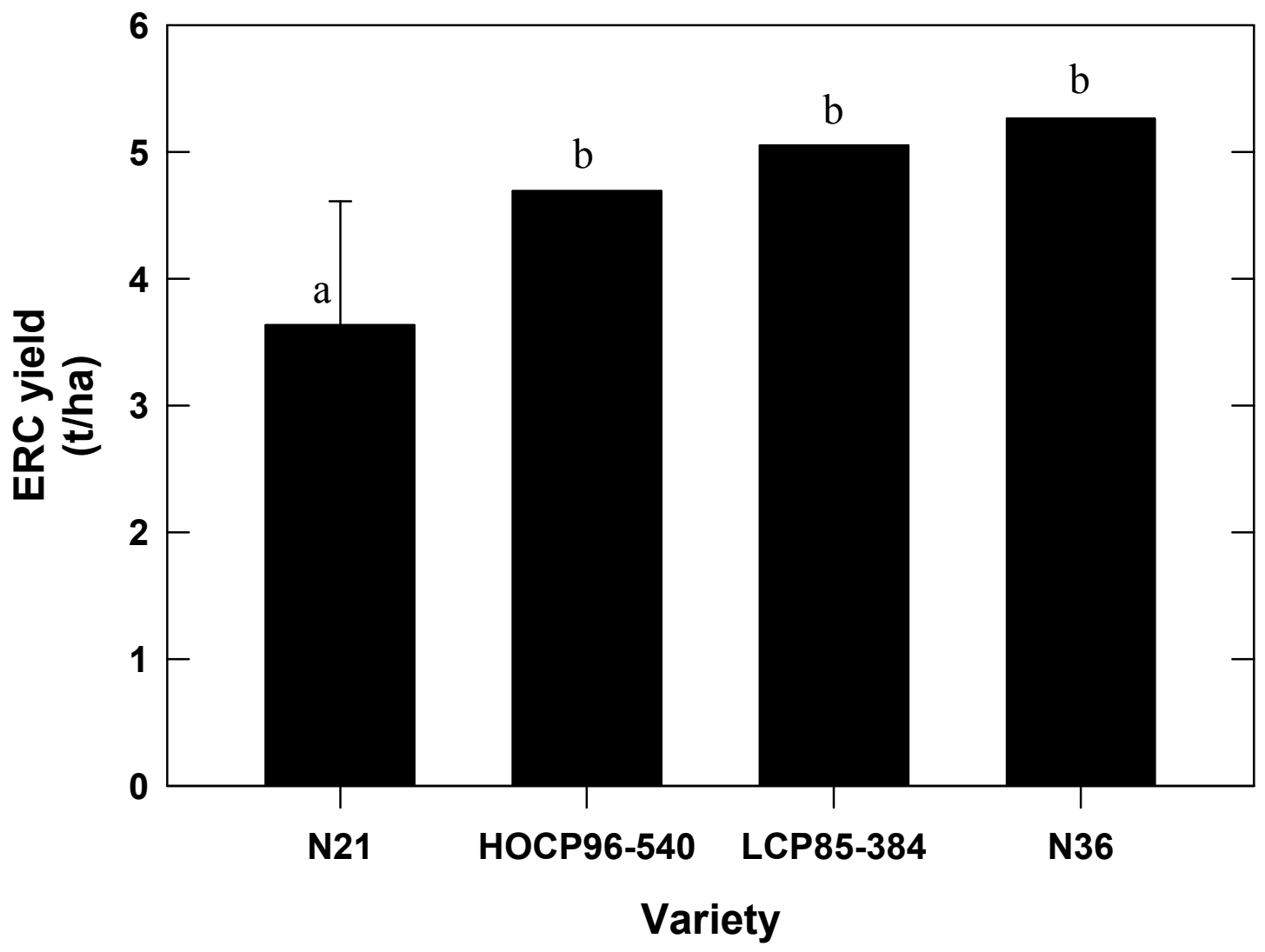

Fig 5.

ERC yields (t/ha) in the four varieties at harvest. The error bar indicates the least significant difference (LSD) at $p<0.05$. Different lowercase letters indicate significant differences $(p<0.05)$ between the varieties 
advantage of HOCP 96-540 over LCP 85-384, that are usually observed under normal growing conditions (Dufrene and Tew 2004), was reversed following frost.

\section{Discussion}

The O-J-I-P fluorescence transient reflects the filling up of the electron acceptor side of PSII ( $\mathrm{Q}_{\mathrm{A}}, \mathrm{Q}_{\mathrm{B}}$ and PQ pool) with electrons from the donor side of PSII (Papageorgiou 1975; Lavorel and Etienne 1977; Strasser and Govindjee 1992). The relationship of these events to the O-J-I-P fluorescence transient was suggested by Strasser et al. (1995) to be the following: $\mathrm{O}$, minimal $\mathrm{Chl}$ a fluorescence yield (highest yield of photochemistry); $\mathrm{O}$ to $\mathrm{J}$, reduction of $\mathrm{Q}_{\mathrm{A}}$ to $\mathrm{Q}_{\mathrm{A}}{ }^{-}$(photochemical phase, light intensity dependent); $\mathrm{J}$ to $\mathrm{I}$ to $\mathrm{P}$, reduction of the PQ pool (non-photochemical phase). Since the O-J-I-P fluorescence transient reflects the kinetics and heterogeneity involved in the filling up of the PQ pool with electrons, it can be used as a sensitive tool to investigate the photosynthetic apparatus in vivo (Strasser et al., 1995). The shape of the O-J-I-P fluorescence transient has been found to be very sensitive to various types of stress (Van Rensburg et al. 1996; Krüger et al. 1997; Lazár and Ilík 1997; Tsimilli-Michael et al. 1999). From the data shown in Figs. 2 and 3 two important observations regarding the effect of frost on the OJ-I-P fluorescence transients in the four sugarcane varieties can be made: a) the shape of the O-J-I-P fluorescence transients recorded in leaves of the varieties following frost exposure differed from those recorded in the leaves prior to the first frost, and b) a conspicuous difference existed between the four varieties with regard to the extent by which the shape of the transients was altered by frost, especially at the J-peak (2 ms). An increase in fluorescence intensity at $2 \mathrm{~ms}$ is usually interpreted as evidence of accumulation of the fraction of reduced $\mathrm{Q}_{\mathrm{A}}{ }^{-}$pool (Strasser et al. 1995; Lazár and Ilík 1997), possibly due to a decrease in electron transport beyond $\mathrm{Q}_{\mathrm{A}}{ }^{-}$(Haldimann and Strasser 1999).

Construction of $\Delta \mathrm{V}$ curves, using the pre-frost O-J-I-P fluorescence rise kinetics for each variety as a baseline, revealed that the first frost induced a perturbation in kinetics of very similar shape and magnitude in all four varieties. However, after further frosts the kinetics were altered in a variety-specific fashion, with clear recovery in N36 and LCP 85-384 towards baseline kinetics. These results depict a typical example of stress 
acclimation where exposure to a light frost hardens the plants to better tolerate subsequent heavier frost. These results suggest that N36 and LCP 85-384 were capable of cold acclimation following the first frost, while N21 and HOCP 96-540 lacked similar capability.

The $\mathrm{PI}_{\mathrm{ABS}}$, which is a sensitive indicator of electron transport efficiency (Krüger et al. 1997; Strasser et al. 2000; Force et al. 2003; Strauss et al. 2007) were calculated from the original O-J-I-P fluorescence transients. Compared to the pre-frost state all varieties showed a decline in $\mathrm{PI}_{\mathrm{ABS}}$ following the first frost, however, N36 and LCP 85-384 then maintained these values for at least a further two weeks longer than N21 and HOCP 96540 where further declines were observed. Maintenance of electron transport efficiency for at least two weeks longer indicates potential for cold acclimation in N36 and LCP 85384 and corroborates the observed recovery in O-J-I-P fluorescence rise kinetics.

The potential for cold acclimation in plants having the $\mathrm{C}_{4}$ photosynthetic pathway was recently demonstrated (Kakani et al. 2008), and in sugarcane varieties the ability to cold acclimate might be related to sensitivity of pyruvate, orthophosphate dikinase (PPDK) and NADP-malate dehydrogenase (NADP-MDH) activity (Du et al. 1999). These authors proposed that the inhibition of NADP-MDH and PPDK activity limited $\mathrm{CO}_{2}$ assimilation capacity with subsequent photoinhibition and upstream damage to the electron transport systems. Sugarcane is a typical NADP-ME subtype $\mathrm{C}_{4}$ plant and contains genes of both tropical and sub-tropical species. It is therefore not surprising that sugarcane is sensitive to low temperature, although differences in sensitivity between hybrid species have been demonstrated ( $\mathrm{Du}$ et al. 1999). These authors found large differences in photosynthetic capacity between three hybrid species during exposure to low temperature. In the hybrid species that was least affected, almost all measured leaf enzyme levels increased during cold exposure and photosynthetic rates also gradually increased by $20-30 \%$ following the initial decline that occurred at the start of exposure (Du et al. 1999). In another study sugarcane plants grown at low temperature for extended periods of time also showed some acclimation of the photosynthetic apparatus (Ebrahim et al. 1998). These previous findings suggest that varying degrees of cold acclimation potential might be present in sugarcane. The results presented in the present 
paper are to the best of our knowledge the first report of cold acclimation ability under field conditions in sugarcane.

These previous findings, and the results presented here, suggest that electron transport capacity is a main target during low temperature stress in sugarcane and that chlorophyll a fluorescence is a sensitive tool for probing the degree of damage and acclimation responses in sugarcane.

The observed cold acclimation in N36 and LCP 85-384 would have enabled maintenance of higher photosynthetic efficiency (as indicated by the $\mathrm{PI}_{\mathrm{ABS}}$ values), and thus also ERC accumulation in the stalks for longer following the first frost event. The results that showed that N36 and LCP 85-384 increased ERC content (\%) by 26\% and $20 \%$ between the pre-frost state and harvest, compared to N21 and HOCP 96-540 where the increase were only $8 \%$ and $11 \%$, supports this suggestion. This would have contributed towards N36 having a 30\% higher ERC yield (t/ha) than N21 as well as the known yield advantage of HOCP 96-540 over LCP 85-384 (Dufrene and Tew 2004) being reversed following frost.

In conclusion, the ability to maintain high ERC accumulation capacity for longer following frost due to cold acclimation could be an important factor determining sugarcane yield performance in frost-prone areas. In addition, O-J-I-P fluorescence rise kinetics show promise as a rapid screening tool for assessment of cold acclimation potential and frost tolerance in sugarcane.

\section{Acknowledgements}

The author acknowledges Mr. Rudolph Koch for provision of land and managing of the field trial on his farm Green Hill (Kwazulu-Natal, South Africa).

\section{References}

Berry J, Björkman O (1980) Photosynthetic response and adaptation to temperature in higher plants. Ann Rev Plant Physiol 31: 491-543 
Du YC, Nose A, Wasano K (1999) Effects of chilling temperature on photosynthetic rates, photosynthetic enzyme activities and metabolite levels in leaves of three sugarcane species. Plant Cell Environ 22: 317-324

Dufrene EO, Tew TL (2004) HOCP 96-540, a chip off the old block? Am Soc Sugar Cane Tech 24: 82

Ebrahim MKH, Vogg G, Osman MNEH, Komor E (1998) Photosynthetic performance and adaptation of sugarcane at suboptimal temperatures. J Plant Physiol 153: 587592

Edwards GE, Nakamoto H, Burnell JN, Hatch MD (1985) Pyruvate, Pi dikinase and NADP-malate dehydrogenase in $\mathrm{C}_{4}$ photosynthesis: properties and mechanism of light/dark regulation. Ann Rev Plant Physiol 36: 255-286

Eggleston G, Legendre B, Tew T (2004) Indicators of freeze-damaged sugarcane varieties which can predict processing problems. Food Chem 87: 119-133

Force L, Critchley C, Van Rensen JJS (2003) New fluorescence parameters for monitoring photosynthesis in plants. Photosynth Res 78: 17-33

Haldimann P, Strasser RJ (1999) Effects of anaerobiosis as probed by the polyphasic chlorophyll a fluorescence rise kinetic in pea (Pisum sativum L.). Photosynth Res 62: 67-83

Kakani VG, Boote KJ, Reddy KR, Lang DJ (2008) Response of bahiagrass carbon assimilation and photosystem activity to below optimum temperatures. Func Plant Biol 35: 1243-1254

Kautsky H, Hirsch A (1931) Neue versuche zur kohlensäure assimilation. Naturwissenschaften 19: 964

Krüger GHJ, Tsimilli-Michael M, Strasser RJ (1997) Light stress provokes plastic and elastic modifications in structure and function of photosystem II in camellia leaves. Physiol Plant 101: 265-277

Lavorel J, Etienne AL (1977) In vivo chlorophyll fluorescence. Top Photosynth 2: 203268

Lazár D, Ilík P (1997) High-temperature induced chlorophyll fluorescence changes in barley leaves: Comparison of the critical temperatures determined from 
fluorescence induction and from fluorescence temperature curve. Plant Sci 124: $159-164$

Osborne CP, Wythe EJ, Ibrahim DG, Gilbert ME, Ripley BS (2008) Low temperature effects on leaf physiology and survivorship in the $\mathrm{C}_{3}$ and $\mathrm{C}_{4}$ subspecies of Alloteropsis semialata. J Exp Bot 59: 1743-1754

Papageorgio J (1975) Chlorophyll fluorescence: an intrinsic probe of photosynthesis. In: Govindjee (ed) Bioenergetics of Photosynthesis, Academic Press, New York, pp 319-371

Rapacz M (2007) Chlorophyll $a$ fluorescence transient during freezing and recovery in winter wheat. Photosynthetica 45: 409-418

Rapacz M, Sasal M, Gut M (2011) Chlorophyll fluorescence-based studies of frost damage and the tolerance for cold-induced photoinhibition in freezing tolerance analysis of Triticale (xTriticosecale Wittmack). J Agron Crop Sci 197: 378-389

Rowley JA (1976) Development of freezing tolerance in leaves of $\mathrm{C}_{4}$ grasses. Aust $\mathrm{J}$ Plant Physiol 3: 597-603

Rowley JA, Tunnicliffe CG, Taylor AO (1975) Freezing sensitivity of leaf tissue of $\mathrm{C}_{4}$ grasses. Aust J Plant Physiol 2: 447-451

Sage RF, Kubien DS (2007) The temperature response of $\mathrm{C}_{3}$ and $\mathrm{C}_{4}$ photosynthesis. Plant Cell Environ 30: 1086-1106

Snyman SJ, Meyer GM, Banasiak M, Nicholson TL, van Antwerpen T, Naidoo P, Erasmus JD (2008) Micropropagation of sugarcane via NovaCane ${ }^{\mathrm{R}}$ : preliminary steps in commercial application. Proc S Afr Sugar Technol Ass 81: 513-516

Strasser BJ, Strasser RJ (1995) Measuring fast fluorescence transients to address environmental questions: The JIP-test. In: Mathis P (ed) Photosynthesis: From light to biosphere. Kluwer Academic Publishers, The Netherlands, Vol V, pp 977980

Strasser RJ, Govindjee (1992) The $\mathrm{F}_{0}$ and the O-J-I-P fluorescence rise in higher plants and algae. In: Argyroudi-Akoyunoglou JH (ed) Regulation of Chloroplast Biogenesis. Plenum Press, New York, USA, pp 423-426

Strasser RJ, Srivastava A, Govindjee (1995) Polyphasic chlorophyll a fluorescence transient in plants and cyanobacteria. Photochem Photobiol 61: 32-42 
Strasser RJ, Srivastava A, Tsimilli-Michael M (2000) The fluorescent transient as a tool to characterise and screen photosynthesic samples. In: Yunus M, Pathre U, Mohanty P (eds) Probing Photosynthesis: mechanisms, regulation and adaptation. Taylor and Francis, London, pp 445-483

Strauss AJ, Krüger GHJ, Strasser RJ, Van Heerden PDR (2007) The role of low soil temperature in the inhibition of growth and PSII function during dark chilling in soybean genotypes of contrasting tolerance. Physiol Plant 131: 89-105

Trischuk RG, Schilling BS, Wisniewski M, Gusta LV (2006) Freezing stress: Systems biology to study cold tolerance. In: Madhava Rao KV, Raghavendra AS, Janardhan Reddy K (eds) Physiology and Molecular Biology of Stress Tolerance in Plants. Springer, Dordrecht, The Netherlands, pp 131-155

Tsimilli-Michael M, Pêcheux M, Strasser RJ (1999) Light and heat stress adaptation of the symbionts of coral reef and temperate foraminifers probed in hospite by the chlorophyll $a$ fluorescence kinetics O-J-I-P. Naturforsch 54C: 671-680

Van Rensburg L, Krüger GHJ, Eggenberg P, Strasser RJ (1996) Can screening criteria for drought resistance in Nicotiana tabacum L. be derived from the polyphasic rise of the chlorophyll $a$ fluorescence transient (OJIP)? S Afr J Bot 62: 337-341 